\title{
Comparison of Supine and Prone Positioning in Female Patients Undergoing Urethral Diverticulum Excision
}

\author{
(D) Naşide Mangır, (D) Richard Inman, (D) Christopher Chapple \\ Royal Hallamshire Hospital, Clinic of Urology, Sheffield, UK
}

\section{What's known on the subject? and What does the study add?}

Excision of female urethral diverticulea (UD) has been traditionally performed in standard lithotomy position. It has been recently suggested that a prone patient positioning might improve surgeon's access to the surgical field and result in improved surgical outcomes. However, up to date there has not been any direct comparison of supine and prone patient positioning during urethral diverticulectomy. This study compares the surgical outcomes of patients undergoing UD excision in supine and prone positions.

\begin{abstract}
Objective: Transvaginal excision of urethral diverticulum (UD) is the gold standard treatment for symptomatic women with UD. Complete UD excision can be challenging due to poor access to the surgical field, especially with proximal, circumferential and recurrent UD. Prone patient positioning has been suggested as an effective way of improving surgical access and vision compared to the traditional supine positioning. However, direct comparison of the two positions is yet to be performed. This study aimed to compare patients who underwent UD excision in prone and supine positions.

Materials and Methods: Prospectively recorded data of 79 women undergoing urethral diverticulectomy between 2004 and 2017 in a single referral centre were reviewed. Patients were operated either in supine or prone positions based on the surgeon's preference. Data collected included patient demographics, UD characteristics on magnetic resonance imaging, intraoperative details and postoperative outcomes. Operative time was calculated from the electronic theatre records starting from the entry of the patient into the operating room to their exit.

Results: The mean patient age was $42.38( \pm 15.24)$ years. More than half of the patients had a recurrent UD at presentation (51.89\%). The mean size of the diverticulum was $25.06( \pm 1.2) \mathrm{mm}$, and the mean operative time was $146.18( \pm 6.0) \mathrm{min}$. UD excision was undertaken in prone position in 50 $(63.3 \%)$ and supine position in $29(36.7 \%)$ patients. Patients in the prone position group were older and had relatively larger and proximal UD. In the multivariable analysis, it was found that a proximally located UD was the main indicator for undergoing surgery in the prone position.

Conclusion: Despite longer operative times, prone patient positioning appears to be the preferred option for patients with larger and proximal UD, presumably because it offers better access to the surgical field.
\end{abstract}

Keywords: Urethral diverticulum, prone position, surgical outcomes

\section{Introduction}

A urethral diverticulum (UD) is an epithelium lined, cystic outpouching of the urethra. UD is thought to arise from repeated infection and dilatation of the Skene's (paraurethral) glands. UD can occur anywhere in the female urethra; however, it mostly affects the middle and distal parts. UD is rare and thus, overlooked. Patients mostly present at ages 30-50 years with a classical triad of postvoid dribbling, dysuria and dyspareunia.
In a population based study in the United States, the annual incidence of UD is reported to be $17.9 \%$ per $10,00,000$ women per year (1).

Current evidence on the natural history and clinical presentation of UD is based on data from retrospective case series, making the evidence base relatively weak. Nevertheless, transvaginal diverticulectomy is the most commonly performed surgical procedure for symptomatic UD treatment. Success rates for urethral diverticulectomy have been around 70\%-86\% with

Correspondence: Naşide Mangır, Royal Hallamshire Hospital, Clinic of Urology, Sheffield, UK

E-mail: nasidemangir@yahoo.com ORCID-ID: orcid.org/0000-0002-3062-6480

Received: 07.02.2021

Accepted: 22.02.2021

Cite this article as: Mangır N, Inman R, Chapple C. Comparison of Supine and Prone Patient Positioning in Female Patients Undergoing Excision of a Urethral Diverticulum. J Urol Surg 2021;8(1):50-53.

${ }^{\circ}$ Copyright 2020 by the Association of Urological Surgery / Journal of Urological Surgery published by Galenos Publishing House. 
reported complications of urethrovaginal fistula (1\%-8\%), de novo stress urinary incontinence (1\%-16\%), recurrent UD (5\%) and recurrent urinary tract infections (UTI) (7\%-31\%) (2).

Many of these complications can be prevented by meticulous surgical dissection around the urethra and sphincter mechanism and by repairing UD in layers. This can be challenging for the surgeon especially in complex cases of circumferentially large and recurrent UD. Vaginal diverticulectomy for female UD is mostly performed in a standard lithotomy position $(3,4)$. Recently, we have described an alternative patient positioning strategy, the modified jackknife position, to optimise surgical access and facilitate surgical excision (5), with equal success and complication rates. However, direct comparison of supine and prone patient positioning during female UD excision has not been performed so far.

In this study, a retrospective analysis was done for perioperative outcomes of patients undergoing UD excision in prone and supine positions.

\section{Materials and Methods}

\subsection{Study Population}

Prospectively recorded case notes of women undergoing a urethral diverticulectomy for symptomatic UD in a single referral centre were reviewed. Patients with complete electronic records from 2004 to 2017 were included. Patient characteristics, diverticulum characteristics on magnetic resonance imaging (MRI) and perioperative data were extracted and recorded.

\subsection{Surgical Technique}

All surgeries were performed by two specialised reconstructive urologists. The decisions to undertake the operations at supine or prone positions were mainly made by the operating surgeon and anaesthetists based on patient and diverticulum factors.

All operations started in supine lithotomy position with rigid cystourethroscopic examination using a $17 \mathrm{Fr}$ cystoscope. Two ureteric catheters were placed in cases where the diverticula were large and/or extended towards the bladder neck to reduce the risk of ureteric injury. After cystoscopy a suprapubic catheter was inserted into the bladder in all patients together with a $16 \mathrm{Fr}$ urethral Foley catheter. Afterwards, the patient was either brought into a prone position or the operation continued in supine position. Prone positioning was performed in close co-operation between the anaesthesiologist and surgical team with the involvement of 4-6 personnel in logrolling the patient into a prone position. Operative time was calculated from the central database starting from the entry of the patient into the operating room to their exit after the operation.

Excision of the diverticulum started by placing a vaginal retractor and injecting 1:200.000 adrenaline/lignocaine solution underneath the vaginal mucosa for hydrodissection. Then, a UD shaped vaginal flap was raised with a sharp dissection. The vaginal mucosal flap was mobilised off the underlying tissues to the level of the bladder neck, and the raised flap was retracted off the field by placing it underneath the central blade of the retractor. Periurethral tissues around the diverticular sac were developed, after which the diverticulum was dissected off the urethral muscle and excised. The urethra was then reconstructed over the Foley catheter using 4/0 Monocryl and figure-of-eight sutures. A watertight closure without any tension on the suture line was achieved. Tissue interposition was performed using preserved periurethral tissues or a Martius flap. Eventually, the vaginal mucosal flap was closed, and the vaginal packs were left inside the vagina.

\subsection{Postoperative Care}

The vaginal pack was removed at the first postoperative day. Intravenous antibiotics were administered for 48 hours after the surgery followed by oral antibiotics for 21 days. Both urethral and suprapubic catheters (SPC) were kept in situ for 21 days. After which a trial without catheter was performed in the clinic. The SPC was removed after a successful trial without catheter. All patients were followed up for 3 months and then discharged to a general practitioner's care if well and symptom free.

\subsection{Statistical Analysis}

Statistical analysis was performed using Statistical Package for the Social Sciences v17.0 software. Descriptive statistics were analysed for statistical significance $(p<0.05)$ using chisquare test and Student's t-test for categorical and continuous variables, respectively. Normal distribution of data was checked using Kolmogorov-Smirnov test.

Table 1. Preoperative characteristics of patients undergoing urethral diverticulectomy

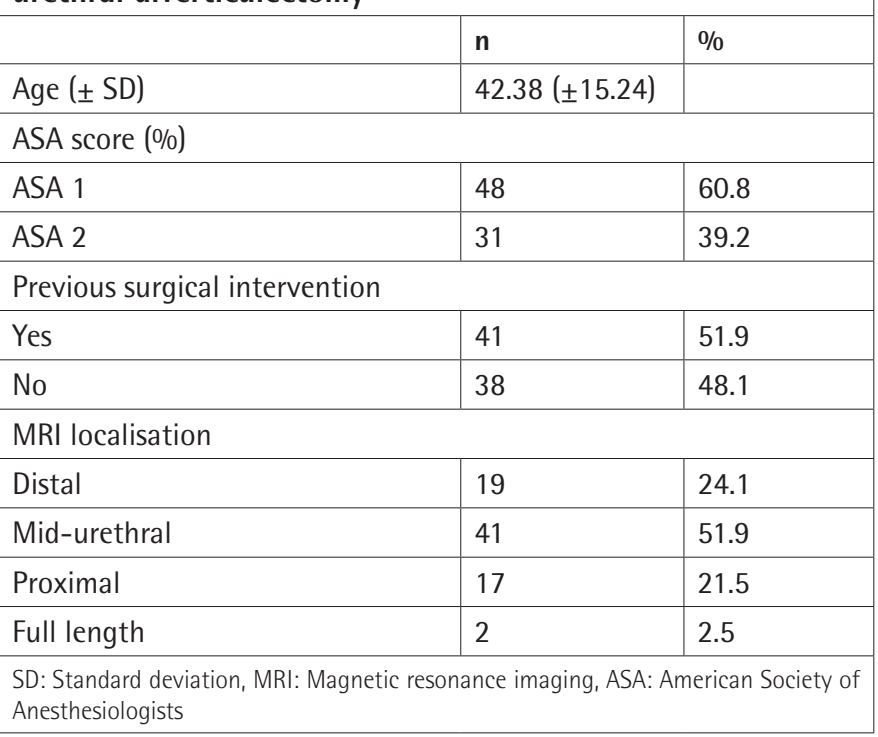




\section{Results}

\subsection{Patient Characteristics}

A total of 79 patients were included in the analysis. The age at presentation was 42.38 (minimum: 18 maximum: 72) years. More than half of the patients (41/79) had previous surgical intervention for UD at the time of presentation (Table 1). All patients had an American Society of Anaesthesiologists score of either 1 or 2 on preoperative evaluation, and all but 1 patient were considered to be unfit for the prone position.

\subsection{MRI Features of the Diverticulum}

All patients underwent postvoid MRI scan to confirm the diagnosis and plan the surgery. The mean size of the diverticulum was $25.0 \mathrm{~mm}$ (minimum: 8 maximum: 48), and most of the diverticula were located in the mid-urethra (51.9\%) followed by distal urethra (24.1\%) and proximal urethra (21.5\%).

\subsection{Perioperative Characteristics}

UD excision was undertaken in prone position in 50 (63.3\%) and supine position in $29(36.7 \%)$ patients. The mean duration of operation was $97.7( \pm 44.6)$ and $171.6( \pm 38.5) \mathrm{min}$ in supine and prone position groups, respectively. Patients in the prone position group were older and had relatively larger and proximal UD (Table 2). On the multivariable analysis of factors of "size of the UD, age and location of the UD", only those with distal UD indicated undergoing a surgery in the prone position.

\subsection{Outcomes}

Table 2. Comparison of peroperative characteristics of patients undergoing excision of urethral diverticulum in supine and prone positions

\begin{tabular}{|l|l|l|l|}
\hline & $\begin{array}{l}\text { Supine } \\
(\mathbf{n = 2 9 )}\end{array}$ & $\begin{array}{l}\text { Prone } \\
(\mathbf{n}=\mathbf{5 0})\end{array}$ & p-value \\
\hline $\begin{array}{l}\text { Mean operative time, minutes } \\
\text { ( } \mathrm{SD})\end{array}$ & $97.7(44.6)$ & $171.6(38.5)$ & 0.001 \\
\hline $\begin{array}{l}\text { Mean diverticulum size }( \pm \\
\text { SD })\end{array}$ & $19.9(8.5)$ & $27.6(11.2)$ & 0.002 \\
\hline $\begin{array}{l}\text { Diverticulum localized at } \\
\text { mid/ proximal urethra }\end{array}$ & $12 / 28$ & $47 / 50$ & 0.001 \\
\hline Patients with prior surgery & $14 / 28$ & $27 / 50$ & 0.39 \\
\hline Age & $33.8(18.4)$ & $46.7(11.2)$ & 0.01 \\
\hline SD: Standard deviation & & \\
\hline
\end{tabular}

The median length of hospital stay was $5.2( \pm 3.5)$ days, and the mean time for removal of catheters was $18.8( \pm 8.5)$ days. The mean follow-up was $7( \pm 6.8)$ months. In $93.6 \%$ of patients, complete resolution of symptoms was achieved. Only 3 (6.4\%) patients continued to have symptoms after excision.
With regards to postoperative complications, one patient had a Martius flap infection that resolved after intravenous antibiotic treatment, one patient had a postoperative UTI needing hospitalisation and one patient failed to empty her bladder in the first trial without catheter. No anaesthesia-related complications were noted.

\section{Discussion}

Urethral diverticulectomy can safely and effectively be performed both in prone and supine positions. Anticipated advantages of prone position include better exposure of the surgical field and tissue planes visualisation especially in cases with more proximal UD. Meticulous dissection of the UD from the surrounding tissues is important in these surgeries as the nerves and blood vessels of the vaginal mucosa are concentrated in the lamina propria (6). Excessive bleeding can occur together with inadvertent damage to the nerves if the anterior vaginal wall dissection is not performed properly avoiding this area. Therefore, dissecting through the avascular plane is essential to achieve better surgical outcomes in UD excision.

In this retrospective series, prone patient positioning seems to prolong the operation time; however, patients in the prone position group had significantly bigger and more proximal UD. The multivariable analysis showed that in our centre, the prone position was preferred over supine positioning in patients with more proximal UD.

We have previously described prone positioning in UD excision. Several other steps were taken to improve surgical field exposure. These include the use of Park's anal retractor and retraction of the buttocks with an adhesive tape. All these measures might have had an effect on surgical outcomes. Additionally, being a referral centre, all the theatre staff and anaesthetists on these surgeries were quite experienced. One can assume that first time users of this position can expect longer operative times with less experienced staff and anaesthetists. Close collaboration and effective communications within the surgical team is essential for the success of this approach.

\section{Study Limitations}

The main limitation of this study is its retrospective nature and selection bias. Patients appear to be selected to prone group when they had a larger and more proximal UD. Also patients in the prone position group were older. Therefore, a selection bias is found in this study.

\section{Conclusion}

Prone patient positioning can be performed safely and effectively when excising urethral diverticulum in females. 
Prone positioning appears to prolong the operative time; however, patients in the prone position group have diverticula that are more difficult to excise. Therefore, a conclusion was not made on why exactly operative times are longer in the prone group in this study. Further studies that compare these two positions are necessary.

\section{Ethics}

Ethics Committee Approval: Ethics committee approval is not necessary for this study as it does not involve any experimentations in animal or human tissues.

Informed Consent: This is a retrospective chart review.

Peer-review: Externally peer-reviewed.

\section{Authorship Contributions}

Concept: N.M., Design: N.M., Data Collection or Processing: N.M., R.I., Analysis or Interpretation: N.M., Literature Search: N.M., Writing: N.M., R.I., C.C.

Conflict of Interest: No conflict of interest was declared by the authors.
Financial Disclosure: The authors declared that this study received no financial support.

\section{References}

1. El-Nashar SA, Bacon MM, Kim-Fine $\mathrm{S}$, Weaver AL, Gebhart JB, Klingele CJ. Incidence of female urethral diverticulum: a population-based analysis and literature review. Int Urogynecol J 2014;25:73-79.

2. Bodner-Adler B, Halpern K, Hanzal E. Surgical management of urethral diverticula in women: a systematic review. Int Urogynecol J 2016;27:9931001.

3. Malde S, Sihra N, Naasire S, Spilotros M, Solomon E, Pakzad M, Hamid R, Ockrim JL, Greenwell TJ. Urethral diverticulectomy with Martius labial fat pad interposition improves symptom resolution and reduces recurrence. BJU Int 2017:1191:158-163.

4. Rufford J, Cardozo L. Urethral diverticula: a diagnostic dilemma. BJU Int 2004;94:1044-1047.

5. Osman NI, Mangır N, Reeves FA, Ricci E, Inman R, Chapple CR. The Modified Prone Jack-knife Position for the Excision of Female Urethral Diverticula. Eur Urol 2021;79:290-297.

6. Mazloomdoost D, Westermann LB, Mutema G, Crisp CC, Kleeman SD, Pauls RN. Histologic Anatomy of the Anterior Vagina and Urethra. Female Pelvic Med Reconstr Surg 2017;23:329-335. 